\title{
Research and Implementation of Network Teaching Platform Based on Web
}

\author{
Xuan Wang ${ }^{1, a^{*}}$, Hongling Zhang ${ }^{1, b}$, Qingzhou Cheng ${ }^{1, c}$, Jing Chen ${ }^{1, d}$ and \\ Nan Qiu ${ }^{2, e}$ \\ ${ }^{1}$ College of Health Science \& Nursing,Wuhan Polytechnic University, Wuhan, China \\ ${ }^{2}$ Wuhan university library, Wuhan, China \\ a495276858@qq.com, ${ }^{\mathrm{b}} 47403115 @ q q . c o m,{ }^{\mathrm{c}} 436276842 @ q q . c o m,{ }^{\mathrm{d}} 116267673 @ q q . c o m$, \\ 150109323@qq.com
}

Keywords: Online teaching; Support platform; Distance education; Web technology.

\begin{abstract}
Nowadays, an effective teaching platform is an important factor in the distance education. In the paper, the structure and functional modules of the teaching platform system based on web technology is studied comprehensively, and these functional modules of the teaching platform is introduced in detail. And the implementation process of the main technical and design principles is generated in the paper. The platform has some function of management and teaching in the education based on multi-layer structure.
\end{abstract}

\section{Introduction}

With the development of Internet technology, database technology, multimedia technology, growth in demand for participation of learners, more and more learners get their knowledge and information by using distance learning style.

The online teaching platform is built on the foundation of the Internet in general above, to provide comprehensive support services for network teaching software systems. A teaching platform based on complete Web consists of three systems: the online curriculum development system, online teaching support systems and online teaching management system, these were completed Web course development, Web teaching implementation and Web teaching management functions. Network teaching platform in teaching systems on the basis of the original, from the teaching process (courseware production and publishing, teaching organization, interactive teaching, learning support and teaching evaluation) full support to the organization and management (managing user and the course) teaching, then the platform can provide the network teaching resources database and manage various education resource that should be integrated [1]. The platform also integrated all kinds of network technology that can build the major subsystems of education, to build a more complicate online teaching support environment.

\section{Network Teaching Platform}

Cyberspace. The so-called virtual private network space, that is, the network provides a storage space and related services to user, so the user can construct their own special work environment according to their own preferences, so in the virtual private network space, it so easy to achieve quick and access to all kinds of network resources that include large data information [2].

And when user used a machine with internet, he can access to his virtual network space as access to his own computer. So, users have a personalized space on mobile learning --- whether in the where, when, you can enter your own online free learning school house.

The Online Classroom. Online Classroom is the main place to implement online learning. Preschool teachers and students can communicate freely at anytime by the online classroom, for example, student can ask some question to teacher by the online classroom before class, after class and in the class. So it can help teacher and students complete all aspects of teaching in effective. 
There are two parts in the online learning and classroom, management of online classroom and learning in classroom learning way for students, management for teachers.

Video on Demand System. Video on Demand (VOD) system is a very important section in the network teaching system, it is mainly to solve the problem of self-learning environment, is an important way to improve the creative ability of students. Students can choose courses from the self-interest of rich IP courseware through video-on-demand system easily [3].

The Online Test System. The online test system, including online self-test and the informal online test, the test system must support both two types. The online test system has some functions, such as proposition, management, automatic test paper, test platform, automatic grading, candidate management, testing and measurement, score publishing capabilities.

Other Systems. Other systems include some functions, such as the forum management system, website statistics systems, materials management systems, article management system, teaching plan management system, personnel management system, rights management systems [4].

\section{The Design of the System}

The system uses a multi-layer structure; it can be classified from the system level, including resource layer, resource management, application logic and presentation layers.

The resource layer of system: the resource including teaching resources (including professional text teaching resources, test database, live classroom, courseware, etc.), the user resource disk space (including network systems, the system can provide database space to users). The users can public some information about class in the Forum; and sometimes student also can upload the job online.

The system also can manage the resources storage, organization and use of resources, furthermore how to storage and organize these education resources is the first question to solve for the resource layer of the system.

And the quality of storage and organize resources is related directly to the quality of the system's performance and usage. In the level, the use of resources and the management of resource should be solved effectively [5].

The Level of Management. The level is responsible for use of resources, including the generation, modify, delete, access, and control of resources. In the level, the resource management have some function: (1) the teaching system based on master-slave network technology is a relatively independent system, it can generate the network virtual Classroom: Teachers can release course syllabus, curriculum implementation in details, the course review, courseware, and other live classroom by the platform. Students can get education resources from any Internet terminal at anytime. In the layer, teachers and students can interact each other freely at anytime and anywhere. In addition, teachers can publish offline job, online test and examinations, and students also can learn or test at any place and at any time by downloading the offline job from the platform [6].

The User Management System. The user management system responsible for user authentication and rights management, which is the basis for other management systems. In the system, all users system is managed in unified management way by the management system.

Forum Management System. The system of forum is responsible for the forum management, the management of forum moderators, and the management forum posts, it is primarily for administrators and teachers.

The VOD System. The system is responsible for some function of video courseware, include increase, delete, and change and check the resource of VOD system. The users can access any type of video courseware through browser.

The Network Test System. The network test system, the system includes some functions, such as the management of test database, paper production, marking and test management. The online test System will provide an online self-test, adaptive form examination and given volume examinations. 
The Article Management System. The system is responsible for all kinds of teaching resources (text, Office, zip, web pages, streaming media and other resources). In the system, teachers can add, delete, change, and check some education information.

\section{Generation of the System}

The Archetecture of System. The platform of teaching system is based on visual studio 2010 development platform, that using $\mathrm{c}$ and .net language in research and development, database using SQL server 2008 as the background database. The language is .net, it is a technology platform, based on the platform of development can be simplified a lot of work. The main benefits of.net language across, cross-platform, security, and support for the open Internet standards and protocols.

In the system, some virtual modeling experiment equipment can be used in it. We adopt using VRML technology used to describe the experimental equipment and its behavior, three-dimensional VRML, it is a kind of modeling language, it is used to describe the three-dimensional objects and their behavior, can build a virtual world, can be integrated text, images, audio, a variety of media types, such as MPEG video can also be embedded programs written in Java [7].

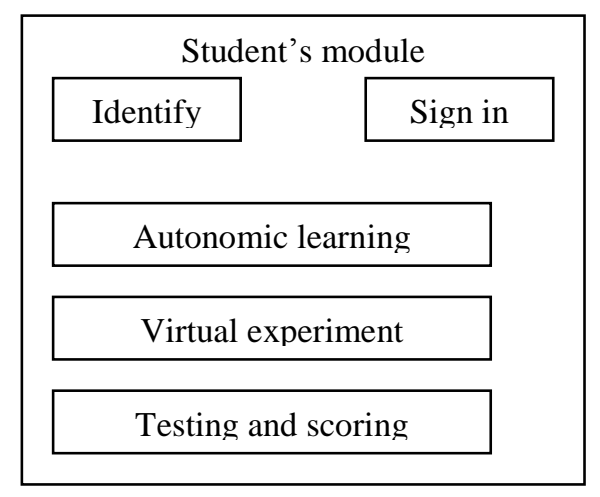

Figure 1. The student module of the platform

The system can be divided in four sections: student module, teacher module and administrator module, lab resources module. These functions be introduced as follows:

The students' module: in the module, student registration, online experiment and the experiment report can be submitted.

The teachers' modules: teacher registration, batch management experiment, the experiment project management, experiment report management, online teaching file to import, online students' attendance;

The administrator module: user authentication management, department management, class management, student management, the management of the term, virtual experiment components management, database management, etc;

The experimental resources modules: professional laboratory is introduced, the rules and regulations introduced, the experiment of the document download, online communication and so on [8].

In the platform, four layers can be shown in the figure 1, in the architecture, students can online computer professional experiment; teachers can arrange experiment project and experiment report online reviews online. Administrator can manage user authentication, classes and professional management. At the same time, according to the experiment the selected device model, need to increase the need for experimental use. Students will also be able to online know each laboratory background and rules will also be able to online to download the required test document [9]. At the same time have a problem we can realize the online communication, first asked to solve the problems in the experiment, as shown in Fig. 2 and Fig. 3 


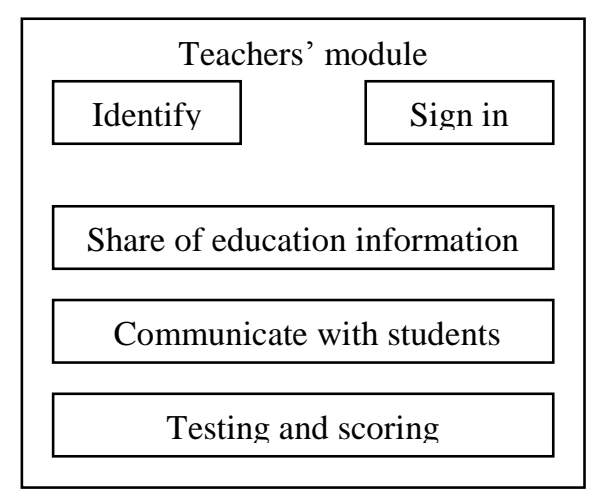

Figure 2. The teachers' module of the platform

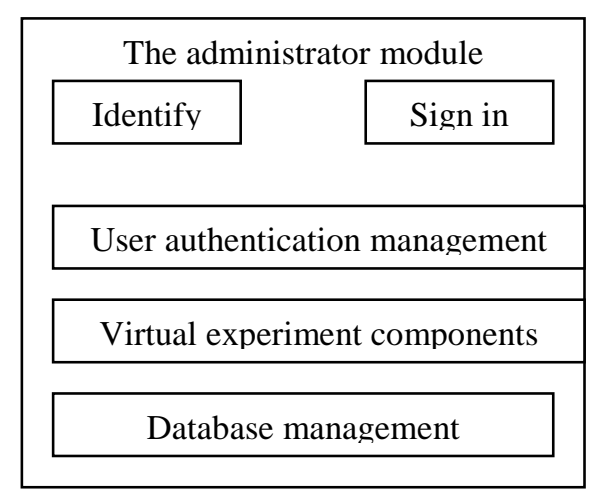

Figure 3. The teachers' module of the platform

\section{Summary}

With the rapid development of network technology, network teaching platform environment has become the prevalent technology. How to use of modern information technology in teaching information technology resources has become an important way of teaching.

At present digital systems and wireless network construction is developing rapidly, future network teaching platform should be able to adapt to the development of these technologies, such as network teaching platform can be incorporated into the school's Card.

With the continuous development of educational technology theory and network technology, research and exploration of network teaching platform will continue in-depth, network teaching platform will also have broad application prospects in modern teaching. Network teaching platform is an important application of digital technology is an important part of the teaching and learning environment, it is a necessary condition way for the Internet-based digitized teaching [10]. At the same time, it can provide the resource that is a base for the creation of a learning society; and the platform also can provide inexhaustible teaching resources for social.

\section{Acknowledgment}

This work and the paper are being supported by the education research project of Hubei province of China (Grant No. 2014324).

\section{References}

[1] G. Eason, B. Noble, and I.N. Sneddon, "On certain integrals of Lipschitz-Hankel type involving products of Bessel functions," Phil. Trans. Roy. Soc. London, vol. A247, pp. 529-551, April 1955. (references) 
[2] J. Clerk Maxwell, A Treatise on Electricity and Magnetism, 3rd ed., vol. 2. Oxford: Clarendon, 1892, pp.68-73.

[3] I.S. Jacobs and C.P. Bean, "Fine particles, thin films and exchange anisotropy," in Magnetism, vol. III, G.T. Rado and H. Suhl, Eds. New York: Academic, 1963, pp. 271-350.

[4] K. Elissa, "Title of paper if known," unpublished.

[5] R. Nicole, "Title of paper with only first word capitalized," J. Name Stand. Abbrev, in press.

[6] Y. Yorozu, M. Hirano, K. Oka, and Y. Tagawa, "Electron spectroscopy studies on magnetooptical media and plastic substrate interface,” IEEE Transl. J. Magn. Japan, vol. 2, pp. 740-741, August 1987 [Digests 9th Annual Conf. Magnetics Japan, p. 301, 1982].

[7] M. Young, The Technical Writer's Handbook. Mill Valley, CA: University Science, 1989.

[8] Kachru,S. and E.F.Gehringer.A comparison of j2ee and net as platforms for teaching web services.2009.

[9] Li,M.and H.Wang.A device management system based on JAVA Web.2009.Wuhan,China.

[10] Ou,J.,et al.Design and research on teaching platform of stage task using JavaEE.2012.Chongqing,China. 